\title{
New Intestinal Schistosomiasis Transmission Foci and Soil-transmitted Helminths Infection After Five Years of Preventive Chemotherapy and Associated Risk Factors Among School-aged Children in Two Districts in Southern Ethiopia
}

Zerihun Zerdo ( $\nabla$ zedozerihun@gmail.com )

Arba Minch University https://orcid.org/0000-0002-6509-4672

\section{Hilde Bastiaens}

University of Antwerp Drie Eiken Campus: Universiteit Antwerpen Campus Drie Eiken

Sibyl Anthierens

University of Antwerp Drie Eiken Campus: Universiteit Antwerpen Campus Drie Eiken

Fekadu Massebo

Arba Minch University

Matewos Masne

Arba Minch University

Gelila Biresaw

Arba Minch University

Misgun Shewangizaw

Arba Minch University

Abayneh Tunje

Arba Minch University

Yilma Chisha

Arba Minch University

Tsegaye Yohannes

Arba Minch University

Jean-Pierre Van geertruyden

University of Antwerp Drie Eiken Campus: Universiteit Antwerpen Campus Drie Eiken

Research Article

Keywords: new foci, Intestinal Schistosomiasis, Soil-Transmitted Helmenthiasis, factors, SAC, Southern Ethiopia 
Posted Date: December 3rd, 2020

DOI: https://doi.org/10.21203/rs.3.rs-118298/v1

License: (c) (i) This work is licensed under a Creative Commons Attribution 4.0 International License. Read Full License 


\section{Abstract}

Background: Preventive chemotherapy (PC), is the main elimination strategy against Soil-Tansmitted Helmenthiasis (STH) and Schistosomiasis (SCH) recommended by the world health organization (WHO), should be strengthened through identification of the remaining $\mathrm{SCH}$ transmission foci and evaluating its impact to get lesson. This study was aimed to assess the prevalence of STH/SCH infections, intensity of infections and associated factors among School Age Children (SAC) in two districts, previously not known to be endemic for SCH in Southern Ethiopia, October to December 2019.

Methods: Structured interview questionnaire was used to collect data, the record of treatment coverage against STH was reviewed and stool samples collected from 2114 children were diagnosed using KatoKatz technique. Multilevel logistic regressions were used to assess the association of infections with potential predictors.

Results: The reviewed treatment coverage ranges from $92 \%$ to $106 \%$ in both districts. The prevalence of STH infection was $33.3 \%$ with $95 \%$ confidence interval $(\mathrm{Cl})$ of $31.3 \%$ to $35.4 \%$. The intensity of infections was light $(93.8 \%, 99.2 \% \& 92.5 \%)$, moderate $(4.7 \%, 0.8 \% \& 7.5 \%)$ and heavy $(1.5 \%, 0 \% \& 0 \%)$ for hookworm, whipworm and Roundworms respectively. STH infection was higher among male SAC with Adjusted Odds Ratio (AOR) of 1.7; 95\% Cl: 1.4-2.1); occupation of the household head other than farmer or house wife (AOR=0.6; 95\% Cl: 0.4-0.9) and with higher wealth index $(\mathrm{AOR}=0.7 ; 95 \% \mathrm{Cl}: 0.5-0.9)$ as compared to the poorest one.

The prevalence of S.mansoni in Dara Mallo district was 34.5\% (95\%Cl: 31.1-38.1\%). Light, moderate and heavy S.mansoni infections were $42.9 \%, 33.7 \%$ and $23.4 \%$ respectively. Children from mothers aged 50 or above years were significantly more likely infected by S.mansoni (AOR=5.9; $95 \% \mathrm{Cl}: 1.4-27.4$ ) as compared to children from mothers (caretakers) of 34 or lower age.

Conclusions: Though high PC coverage were reported, STH remained moderately endemic while S.mansoni became moderate endemic in Dara Mallo, requiring sub-district level mapping and deworming campaign initiations. Evidence based strategies which supplement the existing interventions focusing on the identified factors are important to realize the set targets.

\section{Background}

Soil-transmitted helmenthiasis (STH) and Schistosomiasis (SCH) are the two most common Neglected Tropical Diseases (NTDs) affecting economically deprived people living in warm and moist tropical areas. STH is caused by helminths of the roundworms (Ascaris lumbricoides), the whipworms (Trichuris trichiura) and the hookworms (Ancyclostoma dodenale or Necator americanus). Humans are infected by these helminthes through ingestion of eggs contaminated with soil or penetration of the skin by larvae grown on soil from egg excreted from infected individuals in areas of poor sanitation and hygiene [1]. An estimated 2 billion world population was infected by STHs in 2010: 438.9 million, 819.0 million and 464.6 million were infected by Hookworm, A.lumbricoides and T.trichiura respectively [2, 3]. 
Schistosomiasis ( $\mathrm{SCH}$ ) is caused by blood flukes of the genus Schistosoma. Humans become infected when the larval form of the parasite is released into the water when the snail host penetrates the skin. Transmission of SCH was reported from 78 countries, but $90 \%$ of moderate-to-heavy infections requiring preventive chemotherapy (PC) live in Africa. There are two major forms of $\mathrm{SCH}$ (intestinal and urogenital) with the intestinal form caused by S.mansoni being the most common in Ethiopia [4].

In Ethiopia, about 79 million people, including 25.3 million SAC were living in STH endemic areas while the corresponding numbers for intestinal SCH were 37.3 million and 12.3 million in 2013[5]. The 2013 and 2015 national SCH and STH mapping carried out in Ethiopia revealed that the overall prevalence of STH infection was $21.7 \%$ with the most prevalent parasite being $A$. lumbricoides (12.8\%) followed by Hookworm (7.6\%) and T. trichiura (5.9\%). The burden of SCH was 3.5\% at national level and regional prevalence was $2.6 \%$ in South Nations Nationalities and Peoples Regional (SNNPR) state where the present study area is located. This region was the 2 nd most STH high burden region (42.4\%) next to Gambella (58.1\%) among the nine regional states and two city administrations found in Ethiopia [6].

The morbidity from STH depends on the intensity of infection. It is attributable to their chronic nature and insidious impact on the health and quality of life than mortality. In moderate to heavily infected individuals, STH impairs the physical growth, cognitive development and micronutrient deficiencies leading to poor school-performance and absenteeism in SAC; reduced work productivity in adults and adverse pregnancy outcomes [3].

Symptoms associated with $\mathrm{SCH}$ were due to the reaction of the body to the eggs lodged in the blood vessels. Intestinal SCH can result in abdominal pain, diarrhea and blood in the stool. In advanced stage of the disease, there is enlargement of the spleen and liver, which is associated with accumulation of the fluid in the peritoneal cavity and the hypertension of abdominal blood vessels. In children, SCH causes anemia, stunting and reduced ability to learn. In some chronic cases, $\mathrm{SCH}$ can lead to death. WHO estimated that the annual death rate due to $\mathrm{SCH}$ was 200000 globally[4]

To overcome the morbidities from STH and $\mathrm{SCH}, \mathrm{WHO}$ recommended chemoprevention as a public health intervention to reduce the worm burden among young children, preschool children, SAC, adolescent girls and women of the reproductive age group. Systematic review of published trials indicated that the egg reduction rate of a single dose of drugs ( $400 \mathrm{mg}$ albendazole or $500 \mathrm{mg}$ Mebendazole) used for STH was above the WHO threshold and can be continued to reduce the worm burden and associated morbidities [1]. In contrast to this, there was evidence from Uganda indicating that as the number of rounds of MDA with Praziquantel (PZQ) for the treatment of $\mathrm{SCH}$ increases, the egg reduction rate falls below the recommended threshold of $95 \%$ egg reduction rate[7]. A recently conducted study in Ethiopia concluded that therapeutic efficacy of PZQ $40 \mathrm{mg} / \mathrm{kg}$ was promising on both egg reduction rate and cure rate [8].

Ethiopia has launched the national NTD control program in November 2015 and targeted to eliminate morbidity due to STH and SCH among SAC by 2020 and break transmission by 2025 . There were $100 \%$ geographic coverage and the individual treatment coverage was $77 \%$ and $76.5 \%$ for $\mathrm{SCH}$ and $\mathrm{STH}$ respectively in the 1 st nationwide deworming campaign $[5,9]$. However, the coverage validation survey 
undertaken by one of the authors of this manuscript, as principal investigator in March 2019, indicated that the treatment coverage varied widely per districts ranging from $54.4-91.6 \%$ for STH and $59.7-89.6 \%$ for $\mathrm{SCH}[10]$.

Though PC and other supplementary interventions reduced the prevalence and intensity of STH infections, the reduction was spatiotemporally heterogeneous suggesting stringent monitoring and evaluation of the deworming process to be undertaken in different contexts[11]. A cross-sectional study conducted in agricultural area in Indonesia showed that STH infection remained high after 15 years of deworming campaign between 2003 and 2018. In Indonesia, the prevalence of STH infection was 91.3\% in 2003 and reduced to $57.2 \%$ in 2018 [12].

Depending on the performance of MDA, the reduction in the prevalence of any STH infection varied widely in Kenya. The reduction in the prevalence of STH infection ranged from $90.0-27.5 \%$ after deworming from 2012 to 2017[13]. In similar, the prevalence of SCH infection also remained high as revealed by a study conducted in Tanzania. The prevalence of $\mathrm{SCH}$ infection among the whole population age above 1 year in Ljinga Island in Tanzania was 68.9\%. Despite PZQ treatment was given only for SAC, the highest prevalence of SCH among SAC (86.1\%) indicate that the reinfection was high, warranting for the need of supplementary intervention to achieve elimination and transmission break targets [14]. The reinfection of STH among SAC in Chencha district reached $93.4 \%$ of the baseline prevalence within three months post mass drug distribution campaign [15].

Studies assessing the prevalence of STH and SCH infection revealed that it varied both spatially and temporally. Recent studies conducted in Ethiopia indicated that the prevalence of STH infection with different diagnostic technique ranged from $9.5 \%$ in Gurage Zone in South-central Ethiopia [16] to 52.4\% in southwestern Ethiopia [17]. In Hawassa town, capital of SNNPR, the prevalence of any kind of intestinal parasitic infection was $42.4 \%$ [18]. Articles reviewed originating from other African countries indicated that the prevalence of STH infections ranged from $1 \%$ in a study conducted after two months of MDA in Cameroon [19] to $40.0 \%$ in Kenya [20]. The highest prevalence (57.2\%) was seen in the Agricultural area in Indonesia [12] while it was $27.9 \%$ Myanmar in Asia [16, 21].

STH and SCH infections were common in areas where sanitation and hygiene is poor, in the dry season [17] and with certain socio-demographic characteristics [22]. In contrast to this and biological plausibility, STH infection did not varied with provision of water supply, hand washing facility, sanitation facility, drinking water and provision of behavioral change education and promotion from 2014 to 2017 in Laos [23]. SCH infection was commonly associated with being male gender [24], practices linked to river such as irrigation [25], swimming or crossing river and other sanitation and hygiene related factors [26-28]. The highest prevalence of SCH infection of the reviewed articles [14, 24, 28-31] was seen in Tanzania [14].

$\mathrm{SCH}$ and STH morbidity elimination and transmission breaking targets need consistent monitoring and evaluation of the interventions to get lessons and customize the existing interventions. However, the SCH transmission foci are not exhaustively identified, the impact of the existing interventions on the 
distribution of STH and SCH were poorly addressed in hard to-reach areas like Dara Mallo and Uba Debretsehay districts. Therefore, the present study was primarily aimed to estimate the prevalence of STH and $\mathrm{SCH}$ infections, the intensity of the infections after five years PC against STH among SAC. In addition, factors affecting STH and S.mansoni infections were assessed in Dara Mallo and Uba Debretsehay districts. The findings of this study will be used by decision makers to customize the existing interventions or look for supplementary interventions to accelerate reaching the set targets of morbidity elimination and transmission break of STH and $\mathrm{SCH}$.

\section{Methods}

\section{Study setting}

This study was conducted in Dara Mallo and Uba Debretsehay districts in Gamo and Gofa Zones respectively. Both zones are found in Southern Nations, Nationalities and Peoples Region (SNNPR) state which is the 3rd populous region in Ethiopia. The study area is located in the western part of Arba Minch town, capital of the former Gamo Goffa zone, as indicated in the Fig. 1. Based on the 2007 national census, there were a total of 150,145 people living in the two districts and of whom 76,550 (51\%) were male [32]. According to the recent update of the population by the respective districts, there were a total of 94396 people in Uba Debretsehay district and 110207 people in Dara Mallo district.

\section{Study design and sample size}

A Cross-sectional study was undertaken by recruiting 2114 children from 32 schools in the study area. The number of participants involved in this study was about $91.7 \%$ of the estimated sample size. The sample size estimated was 2304 SAC and their households. The estimated sample size is used to evaluate the effect of malaria prevention education on malaria, anemia and cognitive development among SAC in the study area. This sample size was estimated by using formula recommended to calculate sample size for cluster randomized controlled trials $[33,34]$ for each of the two parallel arms. The assumptions used were $11.04 \%$ and $18.4 \%$ prevalence of malaria with and without the intervention respectively; $95 \%$ level of confidence, $80 \%$ power, 72 cluster size and 0.025 intraclass correlation coefficient (ICC) with the calculated design effect of 2.775 and $15 \%$ loss to follow-up or non-response rate.

\section{Sampling techniques and method of data collection}

A total of 3,204 children attending primary education were approached at 32 primary schools. We had planned to recruit 32 schools by using simple random sampling technique but we had only 32 primary schools in malarious areas in the two districts. Seventy-two children from grade 1 to 3 were selected using systematic random sampling technique from eligible children in each section of the students with a class roster as the sampling frame. All participants involved in the trial were included to address the research objective. The number of participants in the trial from each grade level (grade 1 to 3 ) was determined by the relative contribution of each grade level to the total enrolment of students in each school. Children who were attending their education in the schools during the data collection period were 
included in the study while those mentally not fit to respond to questions directed to them, with physical problems to measure their height, children who did not give stool specimen were excluded from the analysis. Children enrolled to the study were used to trace their households. Participants' households were approached by trained data collectors for interview.

The reported treatment coverage of SAC in each of the included districts was reviewed from records in the district health office and the health department office in Gamo Goffa Zone since the beginning of the campaign in 2015. However, we could get only the report of 2019 from Uba Debretsehay district and 2017, 2018 \& 2019 report from Dara Mallo district.

A pretested, structured questionnaire was used to collect data through face to face interview with mothers or caretakers of the selected children, interviewing the children, observing the toilet structure and its cleanliness condition, took the coordinates of household location using GPS (Global Positioning System). The questionnaire was uploaded to tablets in Open Data Kit (ODK) data collection tool. The data collectors were trained on how to use the data collection tool and ethical procedures. They interviewed mothers or caregivers in conditions when the selected child mother was not alive, interviewed and observed the selected child for its hygiene condition.

\section{Stool examination}

After instructing children on how to collect stool specimen without contaminating with soil or urine and any dirty material, polyethylene screw cupped stool container was given to selected students to bring the stool specimen. The collected stool specimen was transported to Wacha and Beto health centers for laboratory diagnosis within the same day of its collection. Stool smear was prepared following manufacturer's instruction of Kato-Katz thick smear preparation. The prepared stool is left for 30 minutes after preparation and examined under bright field microscope within an hour of smear preparation. The template used for preparation of the smear was $41.7 \mathrm{mg}$ [35]. The number of helminths eggs present in the whole smear was counted and written in laboratory report form designed for this purpose.

\section{Data analysis}

The number of egg count in the whole preparation of kato-katz thick smear and data collected through interview with child mother or caretaker, interview of the selected child and observation of the toilet structure using ODK data collection tool with android version was converted to excel speared sheet by using ODK briefcase. This data is imported to RStudio version 4.0.0alpha and STATA version 14 to predict the principal components (PCA). The variables used in predicting the wealth index of the household were the type of toilet used by the household; the source of drinking water for the household; the presence of sponge mattress in the household, the floor of which the house is constructed; the outer cover of the house, the total number of milk cows in the house; the number of other cows in the house; the number of goats and the number of poultry in the households. The predicted index from PCA is categorized into 4 quartiles to determine the wealth index of the households. The cleaned data were 
subjected to descriptive statistical analysis like the proportion for categorical variables and plots and descriptive measures for continuous data.

The total number of ova counted from the whole preparation of kato-katz thick smear was multiplied by 24 to get the number of ova per gram of stool specimen. This count was used for further classification of the infections into light, moderate and heavy infections. The prevalence of STH infection in each school involved in the study was computed to determine the level of infection, whether it was low, moderate or high endemic [35]. The GPS coordinates taken from each household point was used to calculate the average point to represent the geographic location of the respective schools. Geospatial distribution of endemicity of the infections per schools was presented by using QGIS version 3.12.

The survey data used in this study indicate a hierarchical nature in which children included were nested within the schools. Children within the same school will be similar to each other than students in another school. Thus, mixed effects multilevel logistic regression with random intercepts by schools for STH and S. mansoni infections was used to assess the individual level fixed effects. In the analysis of factors influencing STH and S.mansoni infections, glmer command in Ime4 R package was used. Odds ratio (OR) and corresponding $95 \%$ level of confidence $(\mathrm{Cl})$ were used to assess the strength of association between STH and S.mansoni infections and potential predictor variables. Variables that are significantly associated with STH and S.mansoni infections in univarite multilevel logistic regression were taken to multivariate multilevel logistic regression. The fit of the mode in predicting the outcome variables were checked by Akaike Information Criterion (AIC). The averages of the household coordinates taken by global positioning system (GPS) were used to represent the coordinates of each school. The geospatial data was added to QGIS (Quantum Geographical Information System) to present the infections at school level.

\section{Results}

A total of 2304 SAC were approached to participate in the study, but complete data, including interview, observation and stool specimen was obtained from 2114 participants, giving the response rate of $91.7 \%$. Of the total participated children, $50.2 \%$ were female and the mean age of participating children was 8.7 years ranging from 7-14 years and standard deviation (SD) of 1.5 years. The detail socio demographic, prevalence of STH infection in each category of factors was indicated in Table1. The treatment coverage record reviewed indicates that the reported treatment coverage of PC against SAC in Uba Debretsehay in 2019 was $97.3 \%$ while it was $96 \%$ in Dara Mallo district. The treatment coverage record reviewed indicates that the reported treatment coverage of PC against SAC in both districts was $92 \%$ or above as indicated in Fig. 2 below. 
Table 1

Socio demographic factors and multilevel logistic regression analysis of factors influencing STH infection among SAC

\begin{tabular}{|c|c|c|c|c|c|}
\hline \multirow[t]{2}{*}{ Factor } & \multirow[t]{2}{*}{ Value categories } & \multicolumn{2}{|c|}{ STH infected } & \multirow{2}{*}{$\begin{array}{l}\text { COR(95\% } \\
\mathrm{Cl})\end{array}$} & \multirow[t]{2}{*}{$\operatorname{AOR}(95 \% \mathrm{Cl})$} \\
\hline & & No (\%) & Yes (\%) & & \\
\hline \multirow[t]{2}{*}{ District } & Uba Debretsehay & 1008(73.4) & $365(26.6)$ & $\begin{array}{l}0.4(0.3- \\
0.5)\end{array}$ & $0.4(0.2-0.6)$ \\
\hline & Dara Mallo & $401(54.1)$ & $340(45.9)$ & 1 & 1 \\
\hline \multirow{3}{*}{$\begin{array}{l}\text { Place of } \\
\text { residence }\end{array}$} & Rural & $1166(64.5)$ & $643(35.5)$ & 1 & 1 \\
\hline & Semi-urban & 126(78.3) & $35(21.7)$ & $\begin{array}{l}0.4(0.1- \\
0.9)\end{array}$ & $0.5(0.2-1.5)$ \\
\hline & Urban & 117(81.2) & 27(18.8) & $\begin{array}{l}0.5(0.1- \\
1.6)\end{array}$ & $0.7(0.2-2.2)$ \\
\hline \multirow{2}{*}{$\begin{array}{l}\text { Residence house } \\
\text { is }\end{array}$} & Private & $1345(66.2)$ & 686(33.8) & 1 & \\
\hline & Not private & 64(77.1) & 19(22.9) & $\begin{array}{l}0.8(0.4- \\
1.5)\end{array}$ & \\
\hline \multirow[t]{2}{*}{ Gender of SAC** } & Female & 760(71.6) & $301(28.4)$ & 1 & 1 \\
\hline & Male & 649(61.6) & $404(38.4)$ & $\begin{array}{l}1.7(1.4- \\
2.1)\end{array}$ & $1.7(1.4-2.1)$ \\
\hline \multirow[t]{2}{*}{ Age of SAC } & $7-9$ & $1034(66.4)$ & $523(33.6)$ & 1 & \\
\hline & $10-14$ & $375(67.3)$ & 182(32.7) & $1.0(0.8-1.3$ & \\
\hline \multirow{2}{*}{$\begin{array}{l}\text { Sex of household } \\
\text { head }\end{array}$} & Male & $1298(66.1)$ & $666(33.9)$ & $1.2(0.8-1.9$ & \\
\hline & Female & 111(74.0) & $39(26.0)$ & 1 & \\
\hline \multirow{3}{*}{$\begin{array}{l}\text { Age of household } \\
\text { head }\end{array}$} & $<=34$ & $365(69.3)$ & 162(30.7) & 1 & \\
\hline & $35-49$ & $939(66.1)$ & 482(33.9) & $1.0(0.8-1.3$ & \\
\hline & $>=50$ & 105(63.3) & $61(36.7)$ & $1.0(0.7-1.5$ & \\
\hline \multirow{2}{*}{$\begin{array}{l}\text { Occupation of the } \\
\text { household } \\
\text { head** }\end{array}$} & Farmer/housewife & 1152(63.9) & $652(36.1)$ & 1 & 1 \\
\hline & Others & 257(82.9) & $53(17.1)$ & $\begin{array}{l}0.5(0.3- \\
0.7)\end{array}$ & $0.6(0.4-0.9)$ \\
\hline \multirow{2}{*}{$\begin{array}{l}\text { Educational } \\
\text { status of } \\
\text { household head* }\end{array}$} & Illiterate & 761(65.0) & $409(35.0)$ & 1 & 1 \\
\hline & Literate & $648(68.6)$ & 296(31.4) & $\begin{array}{l}0.8(0.6- \\
1.0)\end{array}$ & $0.9(0.7-1.2)$ \\
\hline \multirow{2}{*}{$\begin{array}{l}\text { Age of child } \\
\text { mother }\end{array}$} & $<=34$ & $923(67.7)$ & $440(32.3)$ & 1 & \\
\hline & $35-49$ & $465(64.9)$ & 251(35.1) & $\begin{array}{l}1.0(0.8- \\
1.3)\end{array}$ & \\
\hline
\end{tabular}




\begin{tabular}{|c|c|c|c|c|c|}
\hline & $>=50$ & $21(60.0)$ & $14(40.0)$ & $\begin{array}{l}1.4(0.6- \\
2.9)\end{array}$ & \\
\hline \multirow{2}{*}{$\begin{array}{l}\text { Educational } \\
\text { status of mother* }\end{array}$} & Illiterate & $989(64.5)$ & $544(35.5)$ & 1 & 1 \\
\hline & Literate & $420(72.3)$ & $161(27.7)$ & $\begin{array}{l}0.7(0.6- \\
0.9)\end{array}$ & $0.9(0.7-1.2)$ \\
\hline \multirow{2}{*}{$\begin{array}{l}\text { Education level of } \\
\text { mother }\end{array}$} & <grade 7 & $222(69.8)$ & $96(30.2)$ & 1 & \\
\hline & >=grade7 & 173(77.2) & $51(22.8)$ & $\begin{array}{l}0.8(0.5- \\
1.3)\end{array}$ & \\
\hline \multirow{2}{*}{$\begin{array}{l}\text { Occupation of } \\
\text { mother* }\end{array}$} & Housewife/farmer & $1264(65.4)$ & $668(34.6)$ & 1 & 1 \\
\hline & Others & $145(79.7)$ & $37(20.3)$ & $\begin{array}{l}0.6(0.4- \\
0.9)\end{array}$ & $0.8(0.5-1.3)$ \\
\hline \multirow{4}{*}{$\begin{array}{l}\text { Wealth index in } \\
\text { quartile* }\end{array}$} & First & $478(61.2)$ & $303(38.8)$ & 1 & \\
\hline & Second & $172(64.4)$ & $95(35.6)$ & $\begin{array}{l}0.8(0.6- \\
1.0)\end{array}$ & $0.7(0.5-0.99)$ \\
\hline & Third & $387(72.5)$ & $147(27.5)$ & $\begin{array}{l}0.7(0.5- \\
0.9)\end{array}$ & $0.7(0.5-0.9)$ \\
\hline & Fourth & $372(69.9)$ & $160(30.1)$ & $\begin{array}{l}0.7(0.5- \\
0.9)\end{array}$ & $0.7(0.5-0.9)$ \\
\hline
\end{tabular}

\section{Prevalence, intensity, endemicity and risk factors of STH infection}

Overall, the prevalence of intestinal helminth infection was $45.6 \%(95 \% \mathrm{Cl} ; 43.5 \%-47.7 \%)$ and infection only by STH was $33.3 \%(95 \% \mathrm{Cl} ; 31.3 \%-35.4 \%)$. The most prevalent STH infection was due to Hookworm $(22.4 \%, n=474)$ followed by Whipworm $(11.4 \%, n=242)$ and Roundworms $(5.9 \%, n=125)$. Apart from intestinal SCH and STH, other intestinal helminth parasite infections identified were H.nana $(\mathrm{n}=86)$, E. vermicularis $(n=43)$ and Taenia species $(n=23)$. Multiple infections among infected individuals were $17.9 \%$ while infection by all three STH parasites was $1.3 \%$. The mean egg count (SD) per gram of stool specimen examined positive for Hookworm, T.trichiura and A.lumbricoides were 483.9(1208.7), $87.9(231.9)$ and $1488(3160.4)$ respectively.

The intensity of infection was light $(93.8 \%, 99.2 \% \& 92.5 \%)$, moderate $(4.7 \%, 0.8 \% \& 7.5 \%)$ and heavy $(1.5 \%, 0 \% \& 0 \%)$ for hookworm, whipworm and Roundworms respectively. The prevalence of STH infection varied widely with schools. Of the total schools involved in this study, in 10, 13 and 9 of the schools, the prevalence was low, moderate and high endemic respectively. In half of the schools $(n=6)$ involved in the study, the prevalence of STH infection was high endemic in Dara Mallo district. The geospatial distribution of low, moderate and high prevalence of infections per schools in each district was depicted in the Fig. 3. 
In multilevel univariable logistic regression, there were different socio demographic as well as sanitation and hygiene related factors that affected infection of a child by STHs. The prevalence of STH infection in Uba Debretsehay district was by $19.3 \%$ lower than its prevalence in Dara Mallo district. The other independent factors those influenced STH infection were place of residence, gender of the child, occupation of the household, education of the household head, education of the child mother( caretaker), occupation of the child mother( caretaker) and economic status of the household. However, after fitting the model to multilevel multivariate logistic regression, gender of the SAC, occupation of the household head and wealth index remained statistically significant. Male SAC were about 1.7 (95\% Cl: 1.4-2.1) times more likely to be infected by STH than the females while children from household head where the occupation of other occupations as compared to being farmer or housewife 0.6 (95\% Cl: $0.4-0.9)$ and wealth index in other quartiles as compared to those in the lower wealth index were about 0.6 and $0.7(95 \% \mathrm{Cl}: 0.5-0.99)$ times less likely infected by STH. The prevalence of STH infections per socio demographic characteristics, their multilevel univariable and multilevel multivariable logistic regression analysis were indicated in Table1.

None of hygiene and sanitation related factors assessed significantly influenced STH infection by SAC after fitting the model in multilevel multivariable logistic regression. Factors that significantly affected the prevalence of STH infection in the multilevel univariable logistic regression were absence of latrine for the household, washing hands before their last meal, using detergents while washing hands before meal, nail of the child being trimmed and cleanliness of the figure nail area. Children with households without toilet $(\mathrm{COR}=1.5 ; 95 \% \mathrm{Cl}: 1.0-2.3)$, children not washed their hand before their last recent meal $(\mathrm{COR}=1.6 ; 95 \% \mathrm{Cl}$ : 1.0-2.6), used soup or ash (COR $=0.6 ; 95 \% \mathrm{Cl}: 0.4-1.0)$ for washing their hand before last meal, trimmed figure nail (COR $=0.8 ; 95 \% \mathrm{Cl}: 0.6-1.0)$, and dirty fingertip around the nail $(\mathrm{COR}=1.4 ; 95 \% \mathrm{Cl}: 1.0-1.8)$ were factors that significantly affected infection of SAC by STHs in multilevel univariable logistic regression. The prevalence of STH infection per sanitation and hygiene related factors and their level of significance in multilevel univariable and multivariable logistic regressions were presented in Table 2 
Table 2

Multilevel logistic regression analysis of sanitation and hygiene related factors influencing STH infection among SAC

\begin{tabular}{|c|c|c|c|c|c|}
\hline \multirow[t]{2}{*}{ Factor } & \multirow[t]{2}{*}{ Value categories } & \multicolumn{2}{|c|}{ STH infected } & \multirow[t]{2}{*}{$\begin{array}{l}\text { COR(95\% } \\
\text { Cl) }\end{array}$} & \multirow[t]{2}{*}{$\begin{array}{l}\mathrm{AOR}(95 \% \\
\mathrm{Cl})\end{array}$} \\
\hline & & No (\%) & Yes (\%) & & \\
\hline \multirow[t]{2}{*}{ Type of household latrine* } & Had latrine & 1332(67.8) & 632(32.2) & 1 & 1 \\
\hline & Open field & $77(51.3)$ & 73(48.7) & $\begin{array}{l}1.5(1.0- \\
2.3)\end{array}$ & $\begin{array}{l}1.4(0.9- \\
2.1)\end{array}$ \\
\hline \multirow[t]{3}{*}{ Toilet cleanliness condition } & Clean & $335(71.9)$ & $131(28.1)$ & 1 & \\
\hline & Somewhat clean & $832(66.5)$ & $419(33.5)$ & $\begin{array}{l}1.4(1.01- \\
1.8)\end{array}$ & \\
\hline & Difficult to walk & $242(61.0)$ & 155(39.0) & $\begin{array}{l}1.5(1.1- \\
2.1)\end{array}$ & \\
\hline \multirow[t]{2}{*}{ Drinking water source } & Others & 1129(67.5) & $544(32.5)$ & 1 & \\
\hline & Surface water & $280(63.5)$ & $161(36.5)$ & $\begin{array}{l}1.1(0.8- \\
1.7)^{-}\end{array}$ & \\
\hline \multirow{2}{*}{$\begin{array}{l}\text { Wash hand before last } \\
\text { meal }\end{array}$} & Yes & 1352(67.3) & $659(32.7)$ & 1 & 1 \\
\hline & No/unknown & $55(54.5)$ & $46(45.5)$ & $\begin{array}{l}1.6(1.0- \\
2.6)\end{array}$ & $\begin{array}{l}1.4(0.9- \\
2.2)\end{array}$ \\
\hline \multirow{3}{*}{$\begin{array}{l}\text { Wash hand before meal } \\
\text { with* }\end{array}$} & Not wash hand & $55(54.5)$ & $46(45.5)$ & 1 & \\
\hline & Only water & 1006(66.8) & $501(33.2)$ & $\begin{array}{l}0.6(0.3- \\
0.9)\end{array}$ & 1 \\
\hline & $\begin{array}{l}\text { Used } \\
\text { soup/others }\end{array}$ & $348(68.8)$ & $158(31.2)$ & $\begin{array}{l}0.6(0.4- \\
1.0)\end{array}$ & $\begin{array}{l}1(0.8- \\
1.3)\end{array}$ \\
\hline \multirow[t]{2}{*}{ Wash hand after toilet } & Yes & 1095(66.4) & $554(33.6)$ & 1 & \\
\hline & No/unknown & $314(67.5)$ & $151(32.5)$ & $\begin{array}{l}1.0(0.8- \\
1.3)\end{array}$ & \\
\hline \multirow[t]{3}{*}{ Wash hand after toilet with } & Not wash hand & $314(67.5)$ & $151(32.5)$ & 1 & \\
\hline & Only water & $430(66.1)$ & $374(33.9)$ & $\begin{array}{l}1.0(0.7- \\
1.3)\end{array}$ & \\
\hline & $\begin{array}{l}\text { Used } \\
\text { soup/others }\end{array}$ & $365(67.0)$ & $180(33.0)$ & $\begin{array}{l}1.0(0.7- \\
1.4)\end{array}$ & \\
\hline \multirow[t]{2}{*}{ Child walking on barefoot } & No & $921(69.2)$ & $410(30.8)$ & 1 & \\
\hline & Yes & $488(62.3)$ & 295(37.7) & $\begin{array}{l}1.1(0.9- \\
1.5)\end{array}$ & \\
\hline
\end{tabular}




\begin{tabular}{|c|c|c|c|c|c|}
\hline \multirow[t]{2}{*}{ Factor } & \multirow[t]{2}{*}{ Value categories } & \multicolumn{2}{|c|}{ STH infected } & \multirow{2}{*}{$\begin{array}{l}\mathrm{COR}(95 \% \\
\mathrm{Cl})\end{array}$} & \multirow{2}{*}{$\begin{array}{l}\mathrm{AOR}(95 \% \\
\mathrm{Cl})\end{array}$} \\
\hline & & No (\%) & Yes (\%) & & \\
\hline \multirow[t]{2}{*}{ Child had shoe to wear } & No & $44(50.6)$ & $43(49.4)$ & 1 & \\
\hline & Yes & 1365(67.3) & $662(32.7)$ & $\begin{array}{l}0.8(0.5- \\
1.3)\end{array}$ & \\
\hline \multirow{3}{*}{$\begin{array}{l}\text { Worn shoe at the time of } \\
\text { interview }\end{array}$} & No shoe to wear & $44(50.6)$ & $43(49.4)$ & 1 & \\
\hline & No & $101(62.3)$ & $61(37.7)$ & $\begin{array}{l}0.8(0.5- \\
1.5)\end{array}$ & \\
\hline & Yes worn shoe & $1264(67.8)$ & $601(32.2)$ & $\begin{array}{l}0.8(0.5- \\
1.3)\end{array}$ & \\
\hline \multirow[t]{2}{*}{ Nail of child is trimmed* } & No & $467(63.5)$ & 268(36.5) & 1 & 1 \\
\hline & Yes & $942(68.3)$ & $437(31.7)$ & $\begin{array}{l}0.8(0.6- \\
1.0)\end{array}$ & $\begin{array}{l}0.9(0.7- \\
1.1)\end{array}$ \\
\hline \multirow{2}{*}{$\begin{array}{l}\text { Cleanliness of finger nail } \\
\text { area* }^{\star}\end{array}$} & somewhat/Clean & 1197(68.9) & $540(31.1)$ & 1 & 1 \\
\hline & Dirty & $212(56.2)$ & $165(43.8)$ & $\begin{array}{l}1.4(1.0- \\
1.8)\end{array}$ & $\begin{array}{l}1.1(0.8- \\
1.5)\end{array}$ \\
\hline
\end{tabular}

\section{Prevalence, intensity of infection and risk factors of SCH in Dara Mallo district}

Except four individuals from Uba Debretsehay district, all infections with S.mansoni were in Dara Mallo district. The prevalence of S.mansoni among SAC in Dara Mallo district was 34.5\% (95\%Cl: 31.1-38.1\%). The mean egg count (SD) of S.mansoni per gram of stool specimen examined positive was 32.6(546.1) and it ranged from 24 to 4728 egg. Of the total S.mansoni infected individuals $42.9 \%, 33.7 \%$ and $23.4 \%$ were light, moderate and heavy infections respectively. The prevalence of S.mansoni infection varied widely per schools involved and it was clustered. The minimum prevalence observed was in Shella Subo primary school $(0.3 \%)$ that is found in Shella cluster while the highest prevalence was observed in Hoya school (91.0\%) which is found in Wacha cluster where Moderate and heavy infections were also common. Concerning the endemicity of infections per schools involved in the study, only 3 out of 12 schools were low endemic, 5 were moderate endemic and 4 were high endemic. The geospatial distribution of S.mansoni endemicity per schools in Dara Mallo district was shown in Fig. 3.

The prevalence of S.mansoni infection was $34.9 \%$ among boys while it was $34.2 \%$ in girls; $37.7 \%$, $28.8 \%$ and $38.0 \%$ among children attending their education in grade one, two and three respectively. Infection of SAC by S.mansoni was significantly affected in multilevel univariable logistic regression by educational status of the household head ( $\mathrm{COR}=1.7 ; 95 \% \mathrm{Cl}: 1.1-2.7)$, age of the child mother (caretaker) (COR = 3.5; $95 \% \mathrm{Cl}: 1.0-14.4)$ and educational status of the child mother (caretaker) (COR $=1.7 ; 95 \% \mathrm{Cl}: 1.1-2.6)$. 
Nonetheless, in multilevel multivariable analysis age of the mother remained statistically significant. Children from mother (caretaker) of the child age above 50 years were about 5.9 times more likely to be infected by S.mansoni infection $(95 \% \mathrm{Cl}: 1.4-27.4)$ as compared to children from mother (caretaker) whose age was less than or equal to 34 years. The detail socio demographic and other factors association in univariable and multivariable logistic regression was depicted in Table 3. 
Table 3

Multilevel logistic regression analysis of factors affecting S.mansoni infection among SAC, 2019

\section{Factor}

Value categories
$\mathrm{SCH}$ infected
$\operatorname{COR}(95 \%$

$\mathrm{Cl})$
AOR $(95 \%$

$\mathrm{Cl})$

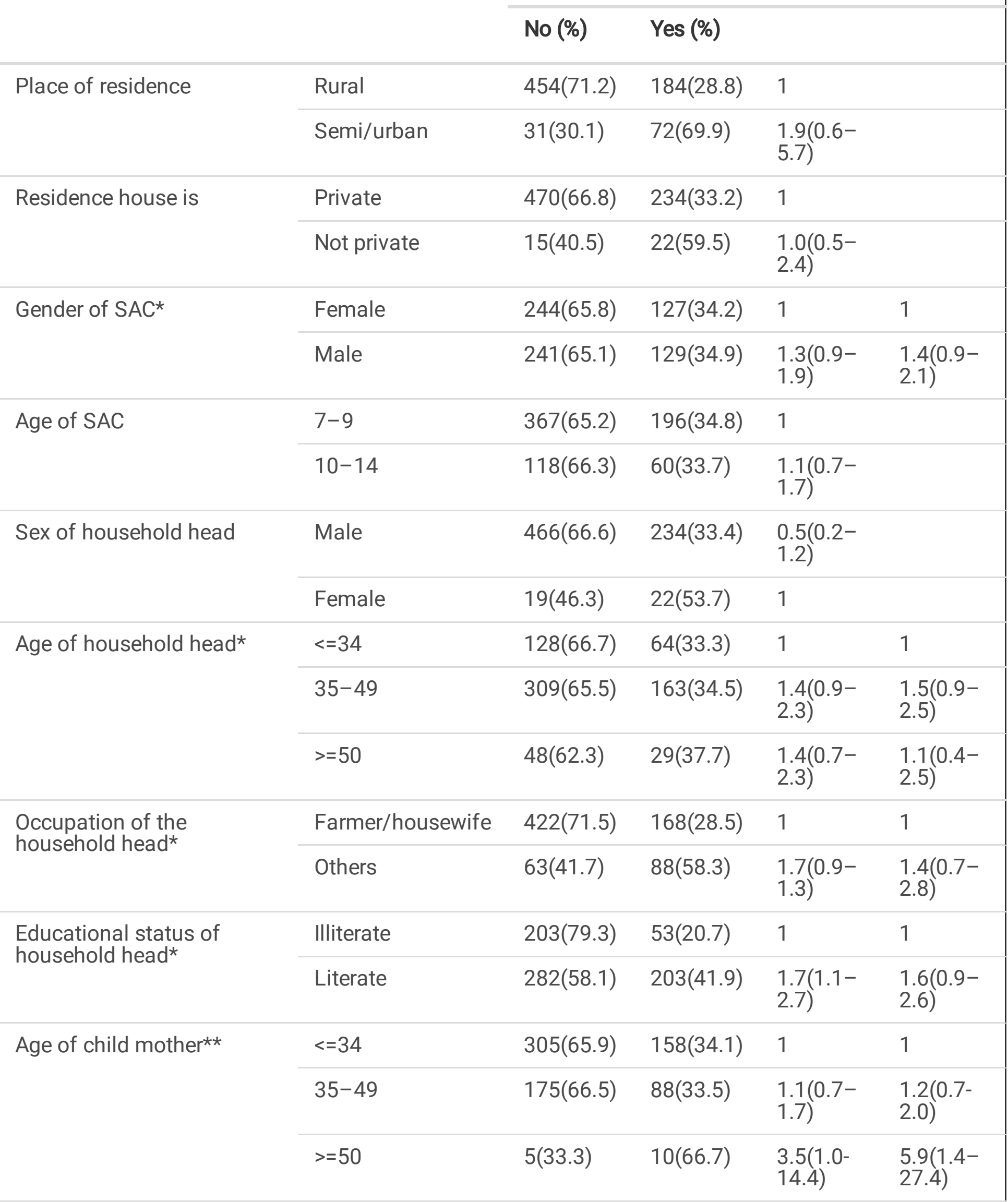




\begin{tabular}{|c|c|c|c|c|c|}
\hline \multirow[t]{2}{*}{ Factor } & \multirow[t]{2}{*}{ Value categories } & \multicolumn{2}{|c|}{$\mathrm{SCH}$ infected } & \multirow{2}{*}{$\begin{array}{l}\text { COR( } 95 \% \\
\mathrm{Cl})\end{array}$} & \multirow{2}{*}{$\begin{array}{l}\mathrm{AOR}(95 \% \\
\mathrm{Cl})\end{array}$} \\
\hline & & No (\%) & Yes (\%) & & \\
\hline \multirow{2}{*}{$\begin{array}{l}\text { Educational status of } \\
\text { mother* }\end{array}$} & Illiterate & $324(76.1)$ & 102(23.9) & 1 & 1 \\
\hline & Literate & $161(51.1)$ & 154(48.9) & $\begin{array}{l}1.7(1.1- \\
2.6)\end{array}$ & $\begin{array}{l}1.4(0.9- \\
2.4)\end{array}$ \\
\hline \multirow[t]{2}{*}{ Education level of mother } & $<$ grade 7 & $83(50.3)$ & $82(49.7)$ & 1 & \\
\hline & $>=$ grade7 & $51(43.6)$ & $66(56.4)$ & $\begin{array}{l}0.8(0.4- \\
1.5)\end{array}$ & \\
\hline \multirow[t]{2}{*}{ Occupation of mother } & Housewife/farmer & $444(68.4)$ & 205(31.6) & 1 & \\
\hline & Others & $41(44.6)$ & $51(55.4)$ & $\begin{array}{l}1.4(0.8- \\
2.7)\end{array}$ & \\
\hline \multirow[t]{2}{*}{ Type of household latrine } & Had latrine & $435(64.1)$ & $244(35.9)$ & 1 & \\
\hline & Open field & $50(80.6)$ & 12(19.4) & $\begin{array}{l}1.1(0.4- \\
2.4)\end{array}$ & \\
\hline \multirow[t]{2}{*}{ Drinking water source } & Others & $418(63.0)$ & $245(37.0)$ & 1 & \\
\hline & Surface water & $67(85.9)$ & $11(14.1)$ & $\begin{array}{l}0.6(0.2- \\
1.4)\end{array}$ & \\
\hline \multirow[t]{4}{*}{ Wealth index in quartile } & First & $234(65.2)$ & $125(34.8)$ & 1 & \\
\hline & Second & $67(72.0)$ & $26(28.0)$ & $\begin{array}{l}0.9(0.5- \\
1.8)\end{array}$ & \\
\hline & Third & $87(65.4)$ & $46(34.6)$ & $\begin{array}{l}1.2(0.7- \\
2.0)\end{array}$ & \\
\hline & Fourth & $97(62.2)$ & $59(37.8)$ & $\begin{array}{l}1.2(0.7- \\
2.0)\end{array}$ & \\
\hline \multirow{2}{*}{$\begin{array}{l}\text { Child had habit of } \\
\text { swimming }\end{array}$} & No & 48(73.8) & $17(26.2)$ & 1 & \\
\hline & Yes & $437(64.6)$ & $239(35.4)$ & $\begin{array}{l}1.0(0.5- \\
2.1)^{-}\end{array}$ & \\
\hline \multirow[t]{3}{*}{ Cross river** } & No river to cross & $291(61.4)$ & 183(38.6) & 1 & 1 \\
\hline & No & $105(70.4)$ & $45(29.6)$ & $\begin{array}{l}0.6(0.4- \\
1.0)\end{array}$ & $\begin{array}{l}0.6(0.3- \\
1.0)\end{array}$ \\
\hline & Yes & $87(75.7)$ & $28(24.3)$ & $\begin{array}{l}0.7(0.4- \\
1.3)\end{array}$ & $\begin{array}{l}0.6(0.3- \\
1.2)\end{array}$ \\
\hline
\end{tabular}

\section{Discussion}


The prevalence of STH infection, infection by S.mansoni, their intensity of infection and infections associated risk factors among SAC after five years of MDA against STH in Dara Mallo and Uba Debretsehay districts were assessed in the present study. The prevalence of infection by any of the three major STH was 33.3\% and moderate-to-heavy infections for A.lumbricoides, Hookworm and T.trichiura were $8.5 \%, 6.2 \%$ and $0.8 \%$ respectively. The corresponding numbers of prevalence and moderate-to- heavy infections for S.mansoni were $35.1 \%$ and $57.1 \%$ in Dara Mallo district. Infection by any STH among SAC in the study area was affected by gender of the child, occupational status of the household head and economic status but none of sanitation and hygiene related factors influenced infection by STHs. S.mansoni infection was higher among children from mothers (caretakers) age 50 or above years.

The prevalence of any STH infection in Uba Debretsehay and Dara Mallo districts remain moderate endemic at the end of 2019 indicating elimination of morbidity target is failed in the area and needs continuation of annual deworming of SAC. The finding of this study was in agreement with Chuahit district [27] in Northern Ethiopia while it was higher than findings of similar studies undertaken in Jima town [17] and Gurage Zone [16] in Ethiopia. In contrast to this, the prevalence of STH infection among SAC in the study area was lower than Hawassa town[18] and west Shewa Zone[22] in Ethiopia. The disagreements in the prevalence of STH infections in these studies could be related to the time of the data collection relative to the year when deworming has started, since deworming could reduce the worm burden and transmission. High prevalence of STH infection in this study area as compared to other studies mentioned above might be due to the high prevalence of STH infection before deworming program was started in Ethiopia or difference in the practice of other STH prevention measures. Except in Kenya [20] and agricultural area in Indonesia [12], the prevalence of STH infection was higher in the current study area than other areas outside Ethiopia. It was higher than the prevalence of STH infection in Cameroon [19, 36], Sudan [30] and Myanmar [21]. The high prevalence observed in Kenya as compared to the current study might be due to year in which the study was conducted. The low prevalence of STH infection in Cameroon could be due to the time in which data collection was carried out. One of the two studies mentioned from Cameroon was undertaken two months post MDA unlike the present study [19] while the difference with Indonesia despite the long time since MDA was started in Indonesia might be related difference in monitoring the deworming campaign to get lesson and take corrective actions accordingly [12].

There were different factors that influenced infection of STH in Uba Debretsehay and Dara Mallo districts. One of the socio demographic factors that influenced STH infection by children was being male. Male children might be more engaged in playing with infected soil outside the houses than females that support their mother and other girls, were more concentrated in activities within the house compounds [12]. This was in agreement with findings from Gurage Zone [16] and T.trichuira infection in Cameroon [36].The other identified factor influencing STH infection was economic level of the household. It is known that STH and other neglected tropical diseases were more common in the economically poor population. This was corroborated in the present study as those in wealth category above the 1st were at decreased risk of infection as compared to the poorest one[1]. A community based study carried out in 
northern Ethiopia also indicated that children aged under five years from households with poor wealth Index were more likely to be infected by intestinal parasitic infections[37].

Poor access to improved water, sanitation and hygiene (WASH) practice was one of the areas for intervention to eliminate STH and SCH. However, improved water source, hand washing after the last recent toilet and before last recent meals by child did not affect child infection by STH. One large scale cluster randomized trial carried out to assess whether provision of water supply, hand washing facility, sanitation facility, drinking water and provision of behavioral change education and promotion from 2014 to 2017 in Laos did not influence STH infection[23]. Similar to this study, a survey undertaken in Gurage Zone[16] and in Jawi town[38] revealed that STH infection is not affected by trimming of nail, playing with soil and open defecation. Another similar study undertaken in West Shewa Zone indicated that untrimmed nail and availability of latrine at household level did not associate with STH infection [22]. Unlike this, other studies carried out in Ethiopia [27, 38, 39] and in countries outside Ethiopia [12, 20] had found a significant influence of WASH related factors on STH infections. The disagreement of these might be linked to social desirability bias as over reporting of positive hygiene behavior than observable real practice of the study participants [40].

The prevalence of S.mansoni in Dara Mallo district was moderate endemic and moderate to heavy intensity of infection was high, though it was left not targeted in the national MDA campaign for the last five years. Wacha cluster, the area where the majority of infections were observed includes the town and the surrounding areas where major irrigation activities are underway. It could be left not noticed because of the sampling issue as sample collected from five schools[6] would not be able to show the full picture of the district. The prevalence of S.mansoni infection in the present study was higher than other studies conducted in Ethiopia such as Jima town near rivers [26], Manna [8] and Chuahit[27] district in northern Ethiopia, Sabatamit (rural Bahir dar) [25] in Northern Ethiopia, in west Shewa Zone[22] and Wondo district in west Arsi Zone[41]. The high prevalence of infection and intensity of infections were due to the absence of periodic MDA to reduce the transmission and morbidity of the infection in the present study area. S.mansoni infection was lower than the prevalence of its infection in Ljinga Island in Tanzania [14] which could be related to difference in the frequency of contact of children with the water body that inhabits S.mansoni infected snails which serve as host for the reproduction of Schistosoma species. Despite it has borderline level of significance, children who had swum habit on water body were at higher risk of infection. In Majority of the studies, infection by $\mathrm{SCH}$ is positively affected by children habit of swimming in water bodies such as in Chuahit [27], Sabatamit rural Bahir Dar [25], west Shewa zone [22] and Korhogo in Côte d'Ivoire[29]. The other independent factor that influenced infection of children by S.mansoni was age of mothers (caretakers) in age 50 or above years. This could be due to women in advanced age may not give due emphasis to protect their children from water bodies that may serve as source of infection.

There was limitation related to this study, thus, those reading this article should interpret the finding in light of this limitation. Cross-sectional study is poor in generating evidence on the causal relationship. The strength of this study was using large sample size to generate evidence on the infection status of 
children on STH and SCH and reaching children in such remote and hard-to-reach areas as this was the 1 st study in its kind in the area.

\section{Conclusion}

Even though the reported treatment coverage of PC against STH in Dara Mallo and Uba Debretsehay districts was above $75 \%$, the prevalence of STH infection remained high in both districts. This implies that achieving morbidity elimination target by 2020 is not achievable. Thus, stringent monitoring of the deworming process and coverage validation survey should be undertaken in order to improve the implementation of the interventions and accelerate the elimination of the disease. More attention should be given to male children and children from low socioeconomic status. The clustered nature of S.mansoni infection in Dara Mallo district pinpoints the importance of sub-district level mapping and initiating PC based on the mapping result. Furthermore, studies focusing on the transmission dynamics and interventions targeting on the snail host shall be considered.

\section{Abbreviations}

AlC: Akaike Information Criterion

AOR: Adjusted Odds Ratio

Cl: Confidence Interval

COR: Crude Odds Ratio

GPS: Global positioning system

IRB: Institutional Research Ethics review Board

MDA: Mass Drug Administration

ODK: Open Data Kit

OR: Odds Ratio

PC: preventive chemotherapy

QGIS: Quantum Geographical Information System

SAC: school-aged children

$\mathrm{SCH}$ : Schistosomiasis

SD: standard deviation 
SNNPR: South Nations Nationalities and Peoples Region

SSA: Sub-Saharan Africa

STH: Soil-transmitted helmenthiasis

WHO: World Health Organization

\section{Declarations}

\section{Ethical consideration}

The trial mentioned elsewhere in this document was approved by the written consent procedure to be followed by the Institutional Research Ethics review Board (IRB) in College of Medicine and Health Sciences at Arba Minch University with the reference number of IRB/154/12.

The trail was registered in Pan African Clinical Trails Registry with a trial ID of PACTR202001837195738. Official request of the permission letter to conduct the research was submitted to district health offices and education offices in Dara Mallo and Uba Debretsehay districts. Support letter written by the respective education offices to support and participate in the study was given to each of the selected schools. The school headmasters were given a support letter from the education offices and written consent was obtained. Parents of the selected SAC were requested to come to the schools and written informed consent was obtained before data collection at school. Written informed consent was obtained from each of the selected students' parent at the school and documented in college of medicine and Health Sciences in Arba Minch University. Children positive in stool examination were treated by using single dose of $400 \mathrm{mg}$ Albendazole for STH and $40 \mathrm{mg}$ of Praziquantel / $\mathrm{kg}$ in two divided doses for S.mansoni.

\section{Consent for publication}

Not applicable

\section{Availability of data and materials}

The datasets used and/or analyzed during the current study will be available from the corresponding author on reasonable request.

\section{Competing interests}

The authors declare that we have no competing interests.

\section{Funding}

Arba Minch University financed the data collection process.

\section{Authors' contributions}


$\mathrm{ZZ}$, JP, HD, SA and FM conceived the idea, designed the study, analyzed, interpreted and drafted the manuscript; MM, MS and YC conceived and involved in acquisition of the data; GB, AT and TY conceived the idea

\section{Acknowledgement}

We would like to thank Arba Minch University for funding the research budget for data collection, London Centre for Neglected Tropical Disease Research for the kind support of kato-katz kits, Dara Mallo and Uba Debretsehay district health offices for informing lists of kebeles. Our sincere appreciation also goes to education offices of both districts and school directors facilitated the data collection process, those involved in the data collection and parents for devoting their time to come to school to provide assent and interview.

\section{References}

1. WHO. Guideline: Preventive Chemotherapy to Control Soil-Transmitted Helminth Infections in At-Risk Population Groups. Geneva: (c) World Health Organization 2017.; 2017.

2. Pullan RL, Smith JL, Jasrasaria R, Brooker SJ. Global numbers of infection and disease burden of soil transmitted helminth infections in 2010. Parasites \& vectors. 2014;7:37.

3. WHO. Soil-transmitted helminthiases: eliminating soil-transmitted helminthiases as a public health problem in children: progress report 2001-2010 and strategic plan 2011-2020.

4. WHO. Schistosomiasis. 2020.

5. Negussu N, Mengistu B, Kebede B, Deribe K, Ejigu E, Tadesse G, et al. Ethiopia Schistosomiasis and Soil-Transmitted Helminthes Control Programme: Progress and Prospects. Ethiopian medical journal. 2017;55(Suppl 1):75-80.

6. Leta G, Mekete K, Wuletaw Y, Gebretsadik A, Sime H, Mekasha S, et al. National mapping of soiltransmitted helminth and schistosome infections in Ethiopia. 2020.

7. Crellen T, Walker M, Lamberton PH, Kabatereine NB, Tukahebwa EM, Cotton JA, et al. Reduced Efficacy of Praziquantel Against Schistosoma mansoni Is Associated With Multiple Rounds of Mass Drug Administration. Clinical infectious diseases : an official publication of the Infectious Diseases Society of America. 2016;63(9):1151-9.

8. Bajiro M, Dana D, Ayana M, Emana D, Mekonnen Z, Zawdie B, et al. Prevalence of Schistosoma mansoni infection and the therapeutic efficacy of praziquantel among school children in Manna District, Jimma Zone, southwest Ethiopia. Parasites \& vectors. 2016;9(1):560.

9. Health FDRoEMo. Ethiopian schistosomiasis and soiltransmitted helminthiasis National Control Programme Year 2 Plan (2016-2017). Addis Ababa, Ethiopia: 2016.

10. Zerdo ZA, M;Churko, C; Teshome, A; Yihune, M; Chisha, Y; Atinaf, H. Coverage of Preventive Chemotherapy Against Four NTDs in Ethiopia, 2019. Arba Minch University, Arba Minch, Ethiopia. 2019. 
11. Assoum M, Ortu G, Basáñez MG, Lau C, Clements ACA, Halton K, et al. Spatiotemporal distribution and population at risk of soil-transmitted helminth infections following an eight-year school-based deworming programme in Burundi, 2007-2014. Parasites \& vectors. 2017;10(1):583.

12. Pasaribu AP, Alam A, Sembiring K, Pasaribu S, Setiabudi D. Prevalence and risk factors of soiltransmitted helminthiasis among school children living in an agricultural area of North Sumatera, Indonesia. BMC public health. 2019;19(1):1066.

13. Mwandawiro C, Okoyo C, Kihara J, Simiyu E, Kepha S, Campbell SJ, et al. Results of a national school-based deworming programme on soil-transmitted helminths infections and schistosomiasis in Kenya: 2012-2017. Parasites \& vectors. 2019;12(1):76.

14. Mueller A, Fuss A, Ziegler U, Kaatano GM, Mazigo HD. Intestinal schistosomiasis of ljinga Island, north-western Tanzania: prevalence, intensity of infection, hepatosplenic morbidities and their associated factors. BMC infectious diseases. 2019;19(1):832.

15. Zerdo Z, Yohanes T, Tariku B. Soil-Transmitted Helminth Reinfection and Associated Risk Factors among School-Age Children in Chencha District, Southern Ethiopia: A Cross-Sectional Study. Journal of parasitology research. 2016;2016:4737891.

16. Weldesenbet $H$, Worku $A$, Shumbej T. Prevalence, infection intensity and associated factors of soil transmitted helminths among primary school children in Gurage zone, South Central Ethiopia: a cross-sectional study design. BMC research notes. 2019;12(1):231.

17. Mekonnen Z, Getachew M, Bogers J, Vercruysse J, Levecke B. Assessment of seasonality in soiltransmitted helminth infections across 14 schools in Jimma Town, Ethiopia. The Pan African medical journal. 2019;32:6.

18. Eyamo T, Girma M, Alemayehu T, Bedewi Z. Soil-Transmitted Helminths And Other Intestinal Parasites Among Schoolchildren In Southern Ethiopia. Research and reports in tropical medicine. 2019;10:137-43.

19. Tabi ESB, Eyong EM, Akum EA, Löve J, Cumber SN. Soil-transmitted Helminth infection in the Tiko Health District, South West Region of Cameroon: a post-intervention survey on prevalence and intensity of infection among primary school children. The Pan African medical journal. 2018;30:74.

20. Worrell CM, Wiegand RE, Davis SM, Odero KO, Blackstock A, Cuéllar VM, et al. A Cross-Sectional Study of Water, Sanitation, and Hygiene-Related Risk Factors for Soil-Transmitted Helminth Infection in Urban School- and Preschool-Aged Children in Kibera, Nairobi. PloS one. 2016;11(3):e0150744.

21. Dunn JC, Bettis AA, Wyine NY, Lwin AMM, Tun A, Maung NS, et al. Soil-transmitted helminth reinfection four and six months after mass drug administration: results from the delta region of Myanmar. PLoS neglected tropical diseases. 2019;13(2):e0006591.

22. Ibrahim T, Zemene E, Asres $Y$, Seyoum D, Tiruneh A, Gedefaw L, et al. Epidemiology of soiltransmitted helminths and Schistosoma mansoni: a base-line survey among school children, Ejaji, Ethiopia. Journal of infection in developing countries. 2018;12(12):1134-41.

23. Chard AN, Garn JV, Chang HH, Clasen T, Freeman MC. Impact of a school-based water, sanitation, and hygiene intervention on school absence, diarrhea, respiratory infection, and soil-transmitted 
helminths: results from the WASH HELPS cluster-randomized trial. Journal of global health. 2019;9(2):020402.

24. Hajissa K, Muhajir A, Eshag HA, Alfadel A, Nahied E, Dahab R, et al. Prevalence of schistosomiasis and associated risk factors among school children in Um-Asher Area, Khartoum, Sudan. BMC research notes. 2018;11(1):779.

25. Workineh L, Yimer M, Gelaye W, Muleta D. The magnitude of Schistosoma mansoni and its associated risk factors among Sebatamit primary school children, rural Bahir Dar, Northwest Ethiopia: a cross-sectional study. BMC research notes. 2019;12(1):447.

26. Tefera A, Belay T, Bajiro M. Epidemiology of Schistosoma mansoni infection and associated risk factors among school children attending primary schools nearby rivers in Jimma town, an urban setting, Southwest Ethiopia. PloS one. 2020;15(2):e0228007.

27. Alemu A, Tegegne Y, Damte D, Melku M. Schistosoma mansoni and soil-transmitted helminths among preschool-aged children in Chuahit, Dembia district, Northwest Ethiopia: prevalence, intensity of infection and associated risk factors. BMC public health. 2016;16:422.

28. Kabongo MM, Linsuke S, Baloji S, Mukunda F, Raquel IDL, Stauber C, et al. Schistosoma mansoni infection and its association with nutrition and health outcomes: a household survey in school-aged children living in Kasansa, Democratic Republic of the Congo. The Pan African medical journal. 2018;31:197.

29. M'Bra RK, Kone B, Yapi YG, Silué KD, Sy I, Vienneau D, et al. Risk factors for schistosomiasis in an urban area in northern Côte d'Ivoire. Infectious diseases of poverty. 2018;7(1):47.

30. Cha S, Elhag MS, Lee YH, Cho DS, Ismail H, Hong ST. Epidemiological findings and policy implications from the nationwide schistosomiasis and intestinal helminthiasis survey in Sudan. Parasites \& vectors. 2019;12(1):429.

31. Lee YH, Lee JS, Jeoung HG, Kwon IS, Mohamed A, Hong ST. Epidemiological Survey on Schistosomiasis and Intestinal Helminthiasis among Village Residents of the Rural River Basin Area in White Nile State, Sudan. The Korean journal of parasitology. 2019;57(2):135-44.

32. Ministry of Health. National Malaria Guidelines. 3rd ed. Addis Ababa: Federal Ministry of Health of Ethiopia; 2012. Available from: https://www.medbox.org/nationalmalaria-guidelinesethiopia/download.pdf; accessed on May 21, 2019.

33. Hayes RJ, Bennett S. Simple sample size calculation for cluster-randomized trials. International journal of epidemiology. 1999;28(2):319-26.

34. Rutterford C, Copas A, Eldridge S. Methods for sample size determination in cluster randomized trials. International journal of epidemiology. 2015;44(3):1051-67.

35. Organization WH. Assessing the efficacy of anthelminthic drugs against schistosomiasis and soiltransmitted helminthiases. 2013.

36. Nkengni SMM, Zoumabo ATC, Soppa NPS, Sizono ABN, Vignoles P, Tchuenté LT, et al. Current decline in schistosome and soil-transmitted helminth infections among school children at Loum, Littoral region, Cameroon. The Pan African medical journal. 2019;33:94. 
37. Gizaw Z, Addisu A, Gebrehiwot M. Socioeconomic Predictors of Intestinal Parasitic Infections Among Under-Five Children in Rural Dembiya, Northwest Ethiopia: A Community-Based Cross-sectional Study. Environmental health insights. 2019;13:1178630219896804.

38. Sitotaw B, Mekuriaw H, Damtie D. Prevalence of intestinal parasitic infections and associated risk factors among Jawi primary school children, Jawi town, north-west Ethiopia. BMC infectious diseases. 2019;19(1):341.

39. Teshale T, Belay S, Tadesse D, Awala A, Teklay G. Prevalence of intestinal helminths and associated factors among school children of Medebay Zana wereda; North Western Tigray, Ethiopia 2017. BMC research notes. 2018;11(1):444.

40. Aiemjoy K, Gebresillasie S, Stoller NE, Shiferaw A, Tadesse Z, Chanyalew M, et al. Epidemiology of Soil-Transmitted Helminth and Intestinal Protozoan Infections in Preschool-Aged Children in the Amhara Region of Ethiopia. The American journal of tropical medicine and hygiene. 2017;96(4):86672.

41. Ansha MG, Kuti KA, Girma E. Prevalence of Intestinal Schistosomiasis and Associated Factors among School Children in Wondo District, Ethiopia. Journal of tropical medicine. 2020;2020:9813743.

\section{Figures}




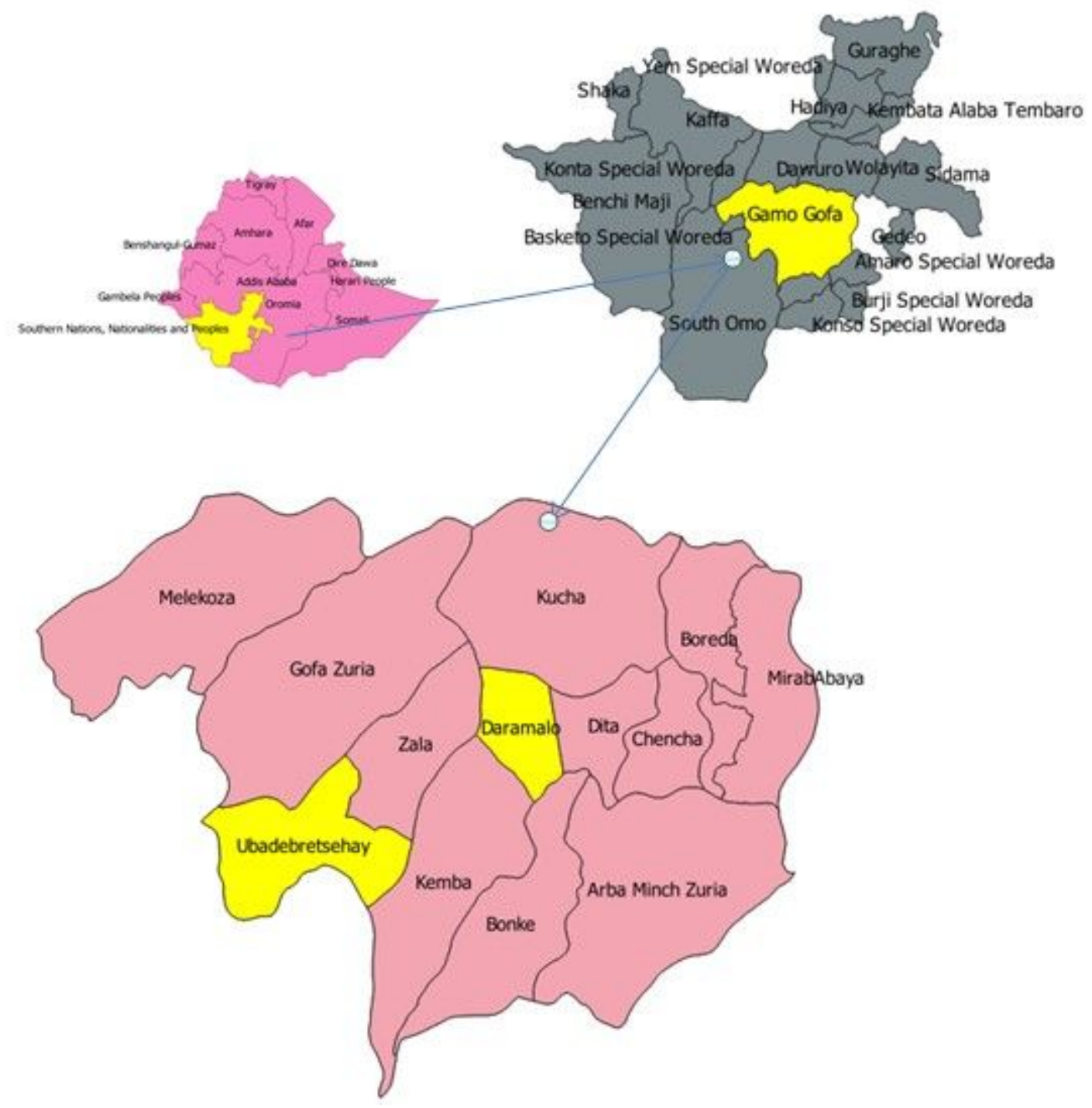

\section{Figure 1}

Location map of two districts selected from former Gamo Gofa zone, SNNPR, Ethiopia. Note: The designations employed and the presentation of the material on this map do not imply the expression of any opinion whatsoever on the part of Research Square concerning the legal status of any country, territory, city or area or of its authorities, or concerning the delimitation of its frontiers or boundaries. This map has been provided by the authors. 


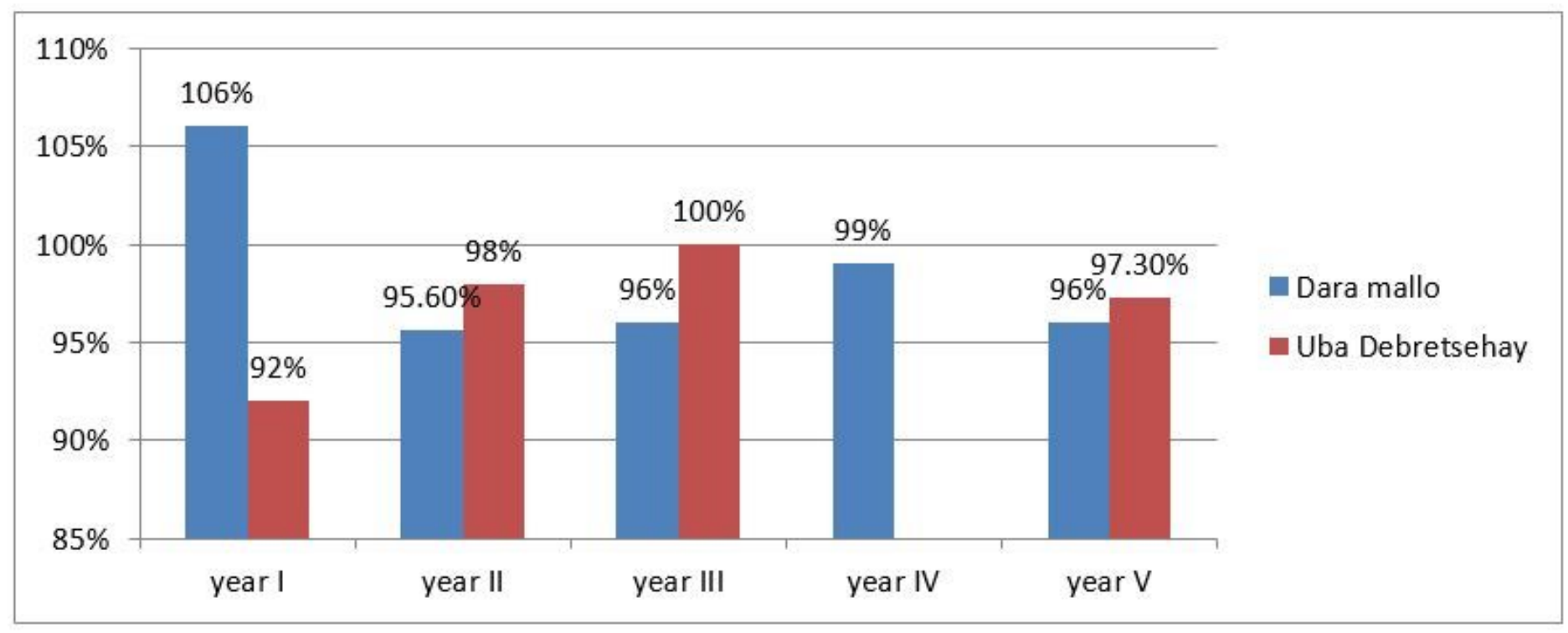

Figure 2

Reported PC coverage against STH among SAC in the study area, 2015 to 2019

\section{Prevalence of STH infection per schools}
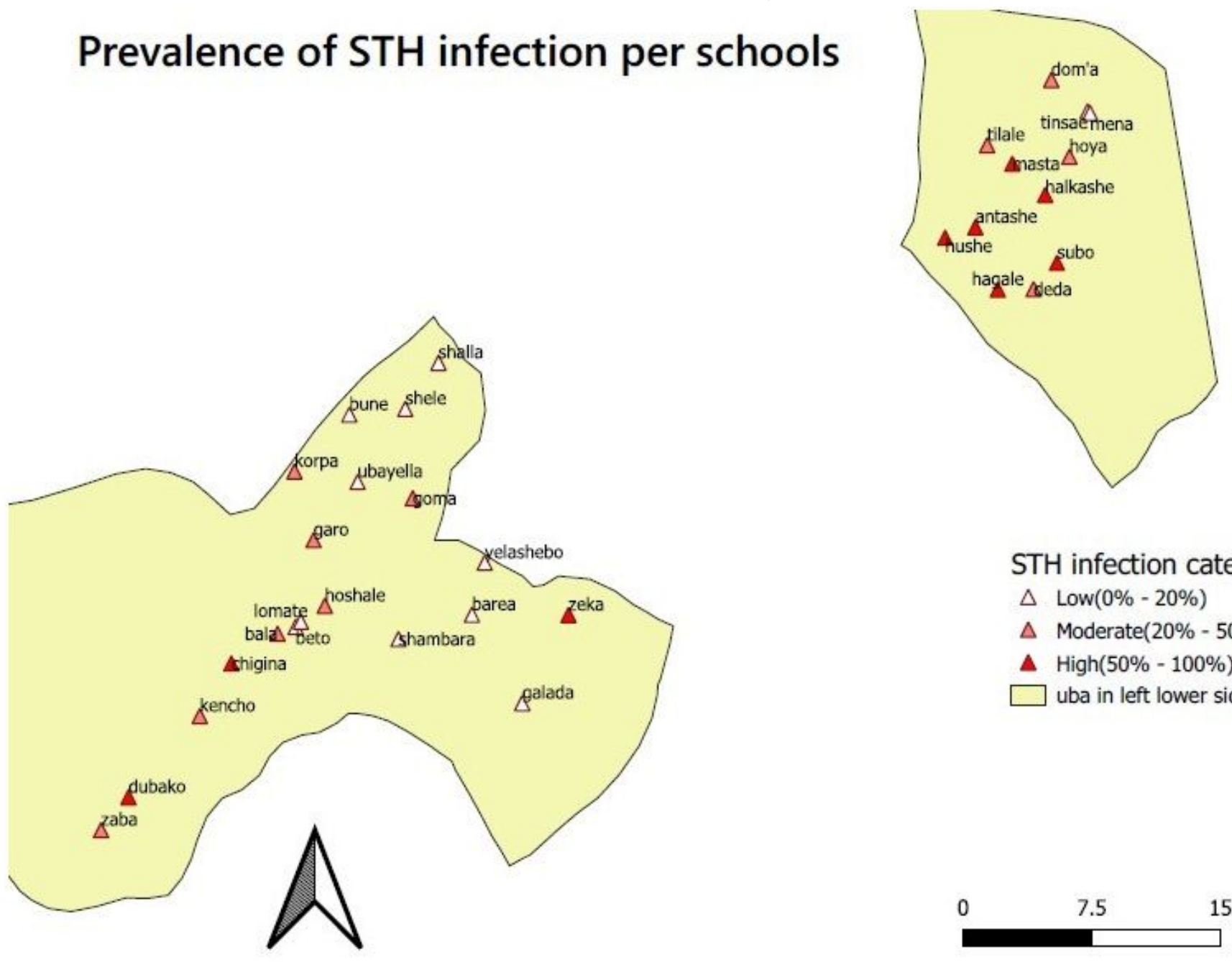

STH infection categories
$\triangle$ Low $(0 \%$ - 20\%)
$\triangle$ Moderate(20\% - 50\%)
A $\operatorname{High}(50 \%-100 \%)$ uba in left lower side and dara

0

7.5

$15 \mathrm{~km}$ 


\section{Figure 3}

Geospatial distribution of Low, Moderate and High STH infection per schools Note: The designations employed and the presentation of the material on this map do not imply the expression of any opinion whatsoever on the part of Research Square concerning the legal status of any country, territory, city or area or of its authorities, or concerning the delimitation of its frontiers or boundaries. This map has been provided by the authors.

\section{Endemicity $\mid$ of SCH per Schools in Dara Mallo district, Southern Ethiopia, 2019}

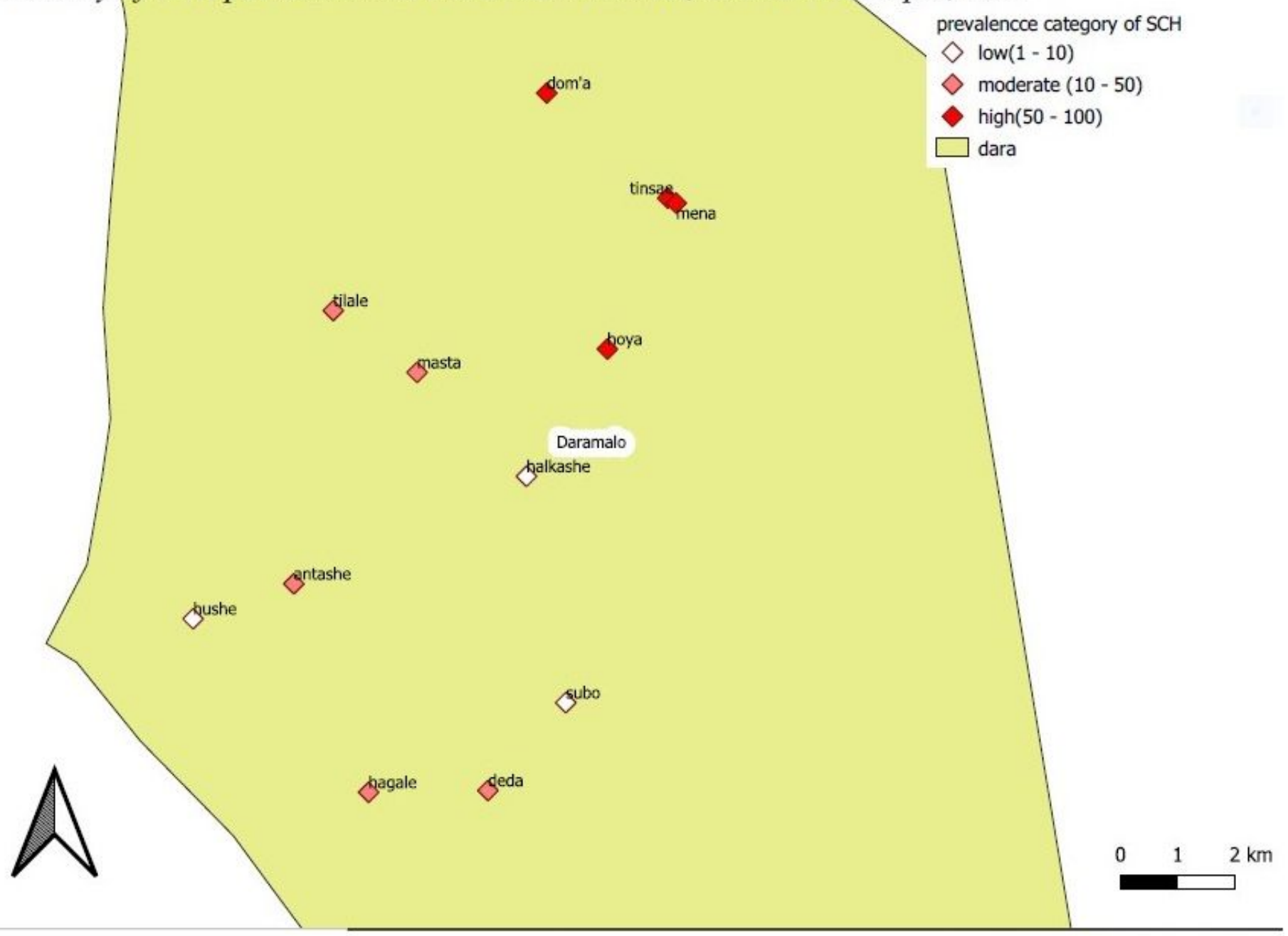

\section{Figure 4}

Geospatial distribution Low, Moderate and High SCH infections per schools in the study area, 2019 Note: The designations employed and the presentation of the material on this map do not imply the expression of any opinion whatsoever on the part of Research Square concerning the legal status of any country, territory, city or area or of its authorities, or concerning the delimitation of its frontiers or boundaries. This map has been provided by the authors. 